UNITED STATES DEPARTMENT OF THE INTERIOR GEOLOGICAL SURVEY

SEISMIC MODEL STUDY OF PATRICK DRAW FIELD, WYOMING--A

STRATIGRAPHIC TRAP IN THE UPPER CRETACEOUS ALMOND FORMATION

by

Robert C. Anderson and Robert T. Ryder

Open-File Report 78-496

1978 


\section{SEISMIC MODEL STUDY OF PATRICK DRAW FIELD, WYOMING - A \\ STRATIGRAPHIC TRAP IN THE UPPER CRETACEOUS ALMOND FORMATION}

Robert C. Anderson and Robert T. Ryder

\section{Abstract}

The Patrick Draw field, located on the eastern flank of the Rock Springs uplift in the Washakie basin of southwestern Wyoming, was discovered in 1959 without the use of geophysical methods. The field is a classic example of a stratigraphic trap, where Upper Cretaceous porous sandstone units pinch out on a structural nose. Two-dimensional seismic modeling was used to construct the seismic waveform expressions of the Patrick Draw field, and to better understand how to explore for other "Patrick Draw" fields. Interpretation of the model shows that the detection of the reservoir sand is very difficult, owing to a combination of acoustic contrasts and bed thickness. Because the model included other major stratigraphic units in the subsurface, several stratigraphic traps are suggested as potential exploration targets.

Introducion

The use of seismic modeling techniques to better identify seismic waveform expressions of subsurface geology has become an important tool in petroleum exploration. The current literature is full of important examples and applications of seismic modeling, which show that modeling has become a common and useful interpretation method to match changing seismic waveform shapes to corresponding changes in stratigraphic facies. The methods of modeling has evolved from the one-dimensional synthetic seismogram using just velocity information and primaries only, to two- and three-dimensional models, which predict the seismic responses of the subsurface. 
This report is the first of a two-part investigation whose major objective is to determine whether or not the Patrick Draw oil field--a classic stratigragraphic trap in the Rocky Mountain area--can be detected with modern reflection seismic techniques. The first phase of the investigation is to generate and interpret a two-dimensional seismic model of the oil field. The second part ties the model into an adjacent Vibroseis common-depth-point (CDP) seismic line. Results of the modeling phase are treated in this report. In addition to the Patrick Draw field, numerous lenticular sandstone units in the adjacent Lewis Shale and Fox Hills Sandstone, some of which produce oil and gas, were also highlighted in the model study.

General Procedures for Stratigraphic Trap Modeling

Two-dimensional seismic modeling is an outgrowth of the techniques of one-dimensional modeling, in which the acoustic parameters from well logs (i.e., the velocity and density data) are converted into synthetic seismic responses using the reflectivity equation. The reflectivity function is then filtered with a seismic wavelet to study the resultant seismic expression that might be found on real field data. It is the reflectivity function and not that wavelet that contains information about geology, such as the composition of rock layers, bed thickness, fluid content, and spatial relationships of the rock unit to other layers in the sequence.

Unfortunately, the modern seismic method does not present the interpreter with a pure reflectivity function. In the simplest case, the reflectivity series is filtered by the natural filtering effect of the earth, and the result is a seismic expression created by the complex averaging of reflection spikes by the earth's filter. This complex averaging operator is commonly referred to as a wavelet, and its effect can be studied through modeling (Sengbush, Lawrence, and McDonal, 1961) by performing a convolution of a wavelet with the 
reflectivity series. Usually, since the real wavelet is never known precisely, simplified wavelets are commonly used, such as the impulse response of a bandpass filter.

A two-dimensional seismic model requires that a geologic cross section be constructed from available well-log information, including the interpreter's idea of geologic style for the area. Data from out of the plane of the cross section can also be projected into the model, if care is taken to avoid contaminating the model with erroneous values. The geologic cross section provides the depth and horizontal coordinates to describe the approximate geometrical configuration of the sedimentary layers. Usually, stratigraphic modeling deals primarily with gently dipping beds, and so the problem of describing curvature of folded beds, as in structural modeling, is reduced. Care does have to be taken in describing the lateral and vertical velocity and density variations of the subsurface, since these parameters play a major role in defining the resultant seismic expression of a rock unit. The seismic expression, sometimes referred to as the signature or reflection character, is the shape or pattern of a reflection in terms of several attributes. Common attributes of a waveform include amplitude distribution, polarity, and frequency characteristics.

The key to producing reasonably accurate models in areas of rapid and complex stratigraphic variations is to simplify the geology from the well logs just enough so that it is economically possible to run the model on a computer, yet without sacrificing the important details of the geology that are being studied. While modeling cannot reproduce every detail of the subsurface, the resulting modeled seismic cross section can often be compared favorably to high-quality field seismic data. 


\section{Geologic Framework}

The Patrick Draw field is located on the eastern flank of the Rock Springs Uplift in the Washakie basin of southwestern Wyoming (fig. 1). The gentle southeast dip of the strata is shown in figure 2. The field produces oil and gas from the Upper Cretaceous Almond Formation, which ranges in depth from $1,167 \mathrm{~m}$ to $1,800 \mathrm{~m}$. Discovered in 1959 without the use of geophysical methods, the field has an estimated 200-250 million barrels of oil in place in the reservoir. Other nearby fields producing from this formation, and from sandstones within the Lewis Shale and Fox Hills Sandstone, are the Desert Springs and West Desert Springs fields, and the Table Rock field. The Desert Springs and West Desert Springs fields produce from updip sand pinchouts to the west, whereas the Table Rock field produces from a closed anticlinal structure south of the Wamsutter Arch (fig. 2). Production from the main Patrick Draw field reservoir is controlled by sand pinchout to the west and north.

A generalized 23-km cross section (fig. 3), constructed along a west-toeast line across Patrick Draw field (fig. 2), shows the boundaries of the major Upper Cretaceous and lower Tertiary strata that were used in the model. The line was chosen to be close to a Vibroseis common-depth-point seismic line, which will be studied later in the second part of the investigation. The cross section in figure 4 shows the stratigraphic units in more detail. These strata consist of complexly intertongued sandstone and shale units of a fluvial, lagoonal, nearshore marine, and open-marine origin. The unconformity at the Lance-Fort Union contact marks the Cretaceous-Tertiary boundary. 
Most of the economic coal deposits are in the Fort Union and Wasatch Formations, whereas oil and gas are produced from the Fox Hills Sandstone, sandstone units in the Lewis Shale, and the Almond Formation. Almond production is primarily from the Patrick Draw, Desert Springs, West Desert Springs, Table Rock, and Wamsutter fields.

The Almond Formation was deposited in front of an advancing Lewis sea and is composed mostly of carbonaceous shale, siltstone, coal, and thin sandstone units of lagoonal and paludal origin. However, in its upper part, nearshore marine sandstone units as much as $15 \mathrm{~m}$ thick and of reservoir quality are locally present. The Patrick Draw field occupies the uppermost part of the Almond Formation where an $8-$ to $10-\mathrm{m}$ thick nearshore sandstone unit is replaced updip by lagoonal deposits. Thus the field is clearly a stratigraphic trap accumulation. According to McCubbin and Brady (1969), the field consists of two overlapping sand bars, each with a separate oil-water contact.

\section{Generation of the Two-Dimensional Model}

To construct the two-dimensional seismic model, acoustic parameters from available sonic and density logs in the field were added to the stratigraphic cross section in figure 4. Even with the simplifications introduced into the model, its size in terms of the number of data points was still so large that the model was split into two equal parts. The reason for modeling strata other than the Patrick Draw reservoir rocks was to provide a complete seismic response picture of the subsurface. In stratigraphic areas like this, it is possible that other combinations of stratigraphy will produce seismic responses very similar to the Patrick Draw field response, and it would be useful to know if such combinations exist. The remainder of this paper will be concerned with just the western half of the model. 
Figure 5 is the final computer-drawn representation of the western half of the geologic cross section used in the model. Some of the finer details of geology have been omitted, such as very thin beds and interfingering of some of the layers. Average velocity of the Patrick Draw reservoir sandstone was $3.5 \mathrm{~km} / \mathrm{s}$, and the average density was $2.35 \mathrm{gm} / \mathrm{cm}^{3}$. From the velocity information provided to the model from sonic logs, the two-way travel time representation of the subsurface was computed (fig. 6). The general structural features of the subsurface remain very much the same as in the depth model, since lateral velocities in the rock change gradually.

The Almond reservoir sandstone occurs at a depth equivalent to a two-way time of from 0.6 to 1.0 seconds, and has a time thickness of 5 to 6 milliseconds. To resolve the individual interfaces of a bed this thin would require seismic frequencies centered around $96 \mathrm{~Hz}$, assuming that the threshold of resolution occurs at a quarter wavelength of the seismic waveform. Obtaining this highfrequency seismic data is pushing the limits of today's recording technology. Fortunately, thin beds can show up on seismic data as a composite waveform response that results when interference between the top and bottom reflection of the bed produce measureable changes in reflection amplitude and frequency content of the waveform. It is this phenomenon, called tuning, that we hope to see on the final seismic model.

Finally, to obtain the simulated seismic cross section, the time section was converted to a two-dimension reflectivity series model using the acoustic parameters, and this reflectivity series was then convolved with a wavelet to produce the section in figure 7 . In this case the wavelet was a symmetric bandpass wavelet with an $8-$ to $70-\mathrm{Hz}$ range. Random noise was not added to the model. 


\section{Interpretation}

The bright events showing up near the top and middle of the section in the Wasatch and Fort Union Formations are thin coal beds with low velocities and low densities. The Lance Formation is seismically quiet, while the top of the Fox Hills Sandstone is a strong reflector. Within the Fox Hills are intertonguing reflections of sand and shale beds, with sand pinchouts occurring near the bottom of the formation. The Lewis Shale is seismically quiet, and the top of the Almond Formation shows up as a good reflection. Unfortunately for the explorationist, however, the Patrick Draw sand reservoir does not manifest itself on the model, either as a separate reflection or as an amplitude change.

Nature has provided the explorationist a resolving problem for the Patrick Draw field. Figure 8 is a diagrammatic plot of the relationship between seismic acoustic impedance and bed thickness. Because of the combination of acoustic contrasts between geologic layers and the thinness of the reservoir sand, the region that contains the Patrick Draw reservoir is somewhere seismically invisible or is a gray zone. Note from the plot that thin beds can be resolved seismically if the acoustic contrasts are high enough.

Figure 9 shows a portion of the lower eastern part of the model. This is a picture of the reflectivity series only, without the wavelet applied. The sand buildup in this part of the section is approximately $10 \mathrm{~m}$. The top of the sand is a strong spike with positive polarity. Updip, the sand thins and the two spikes merge together. It is the configuration of this spike series and the seismic frequencies used that results in destructive interference between the top and bottom of the sand. The final resultant waveform, shown in figure 7 , is a composite waveform that is not much different in shape and amplitude than the reflection waveform in the non-sand case. 
However, there are other events appearing on the model that should be of interest for oil and gas exploration. Figure 10 shows the lower east corner of the model again, but with the $8-$ to $70-\mathrm{Hz}$ wavelet applied. Several sand pinchouts show up seismically, and some of these are as thin as the Patrick Draw reservoir sand. The sandstone in the Almond Formation labeled "Table Rock sandstone" (informal terminology) produces gas in the Table Rock structure about $8 \mathrm{~km}$ to the east and can be seen in a pinchout configuration here. Another sand pinchout is also visible in the Almond Formation and might be an exploration target further to the north.

There are also sandstone units thinning out near the top of the Lewis Shale, and some of them have been noted for producing gas in this area.

In summary, the model study indicates that the Patrick Draw field cannot be detected with the standard range of seismic frequencies, or with a measurement of amplitude changes. Moreover, owing to the low reflectivity coefficients and thinness accompanying the reservoir, it is unlikely that high-resolution seismic data would significantly change the results. Further work is needed to determine what other acoustic parameters, if any, might be used to help explore for Patrick Draw-type fields. It is encouraging to note that other potential exploration targets, such as the 10- to 30-m thick lenticular sandstone units in the Lewis Shale and Fox Hills Sandstone, are commonly visible on the model. 


\section{Selected References}

Lewis, J. L., 1961, The stratigraphy and depositional history of the Almond Formation in the Great Divide Basin, Sweetwater Co., Wyoming, in Wyoming Geological Association Guidebook, 16th Annual Field Conference, p. 87-95. McCubbin, D. G., and Brady, M. J., 1969, Depositional environment of the Almond reservoir, Patrick Draw Field, Wyoming: The Mountain Geologist, v. 6, no. $1, \mathrm{p} .3-26$.

Sengbush, R. L., Lawrence, P. L., and McDonal, F. J., 1961, Interpretation of synthetic seismograms: Geophysics, v. 26, no. 2, p. 138-157.

Weimer, R. J., 1965, Stratigraphy and petroleum occurrences, Almond and Lewis Formations (Upper Cretaceous), Wamsutter Arch, Wyoming, in Wyoming Geological Association Guidebook, 19th Annual Field Conference, p. 65-80. 


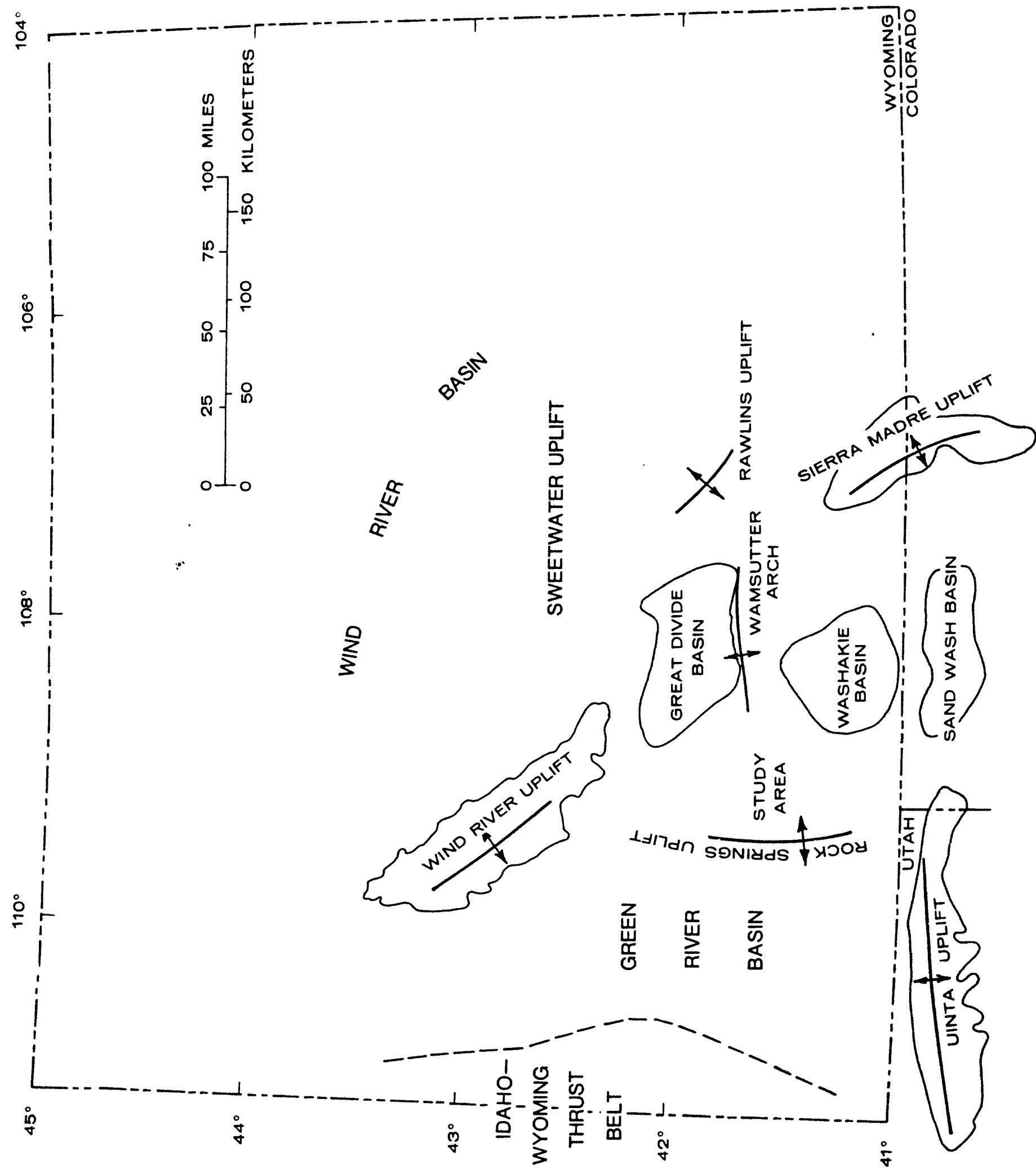

Figure 1 -- Index map of Green River Basin in southwestern Wyoming, showing location of study area and its relationship to other tectonic features. 


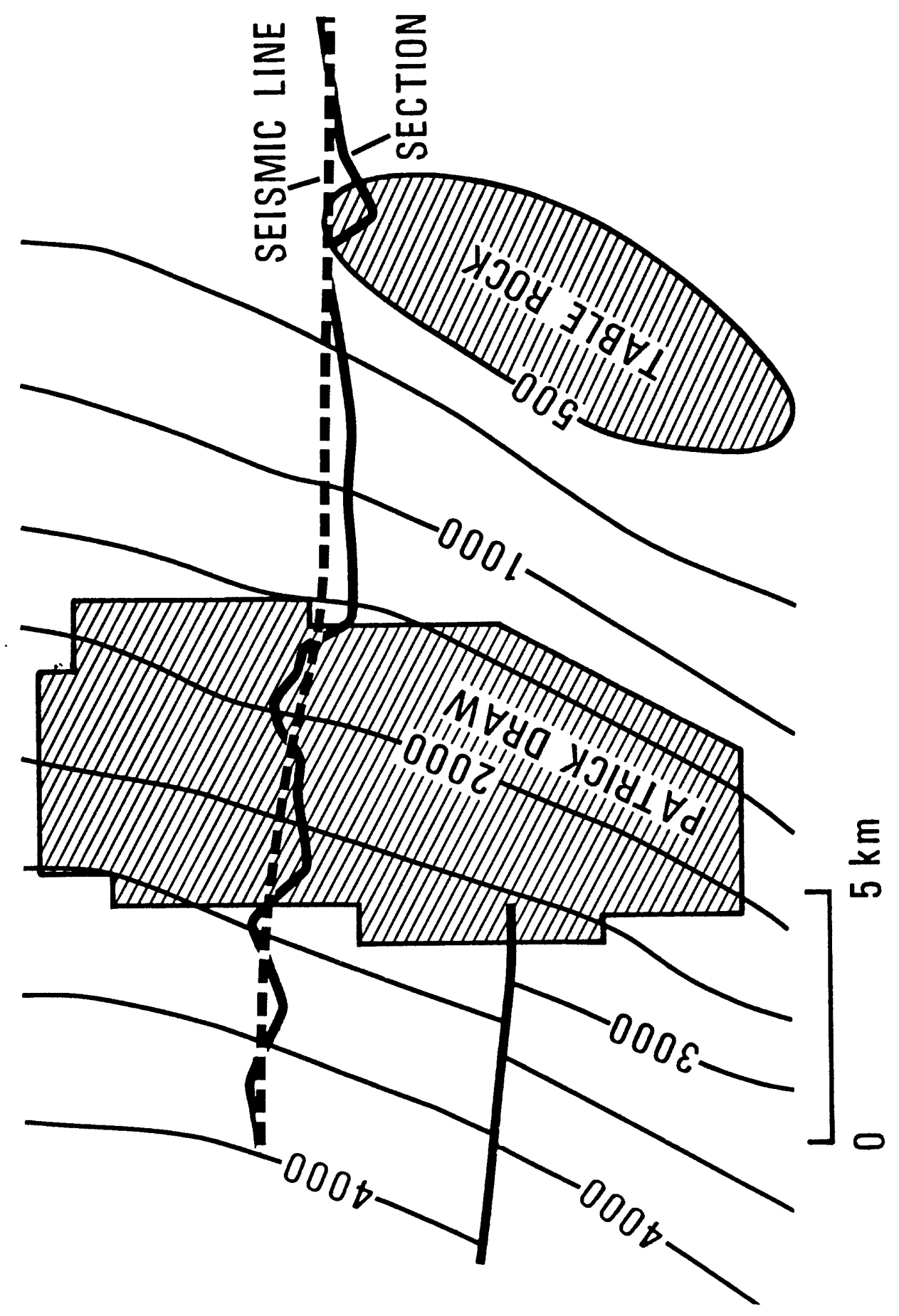

Figure 2 -- Generalized outline of the Patrick Draw field showing location of the stratigraphic cross section shown in figures 3 and 4. Structure contours (in feet) are on top of the Almond Formation. 


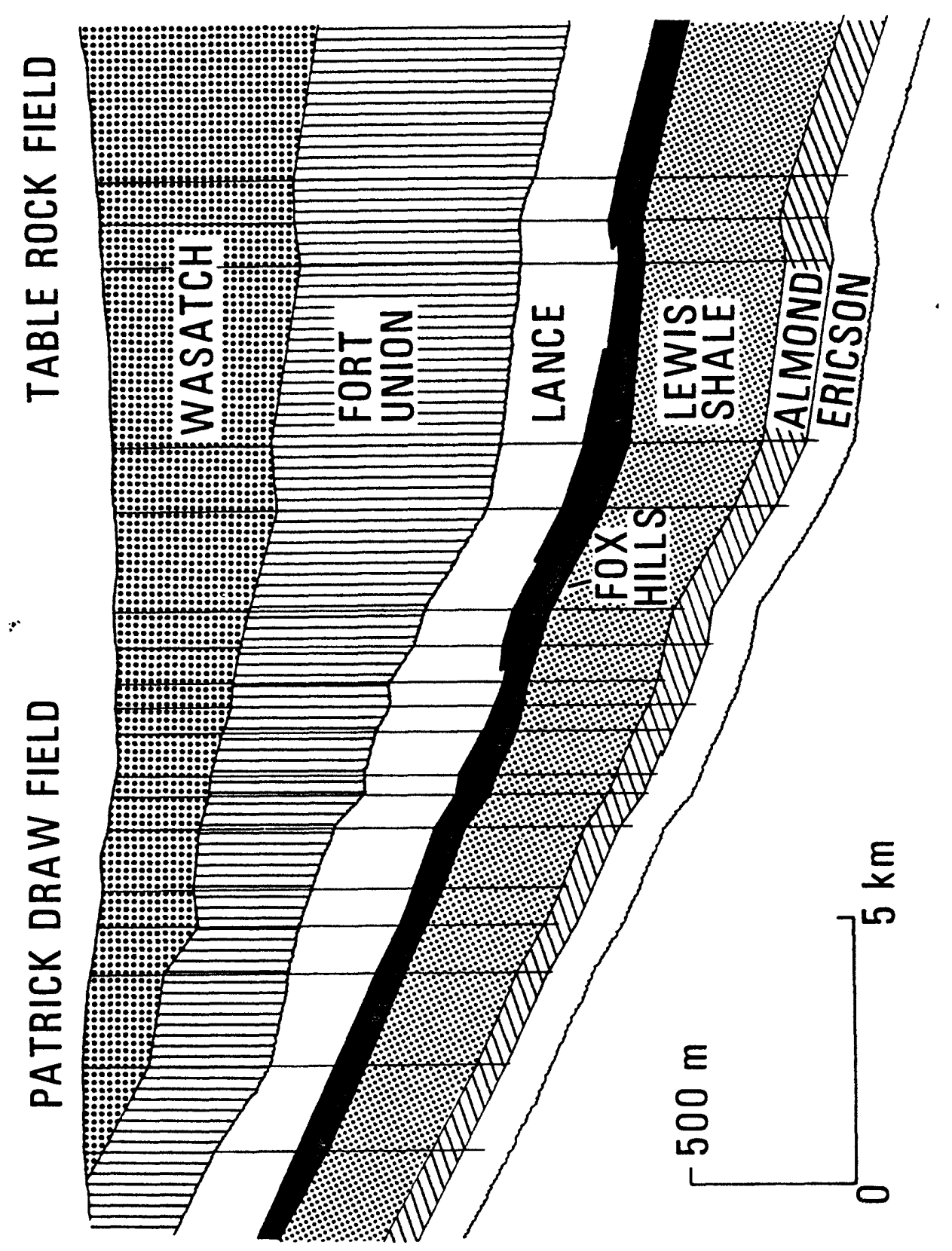

Figure 3 -- Generalized stratigraphic cross section of Patrick Draw and Table Rock fields. Location of cross section is shown in figure 2 . 


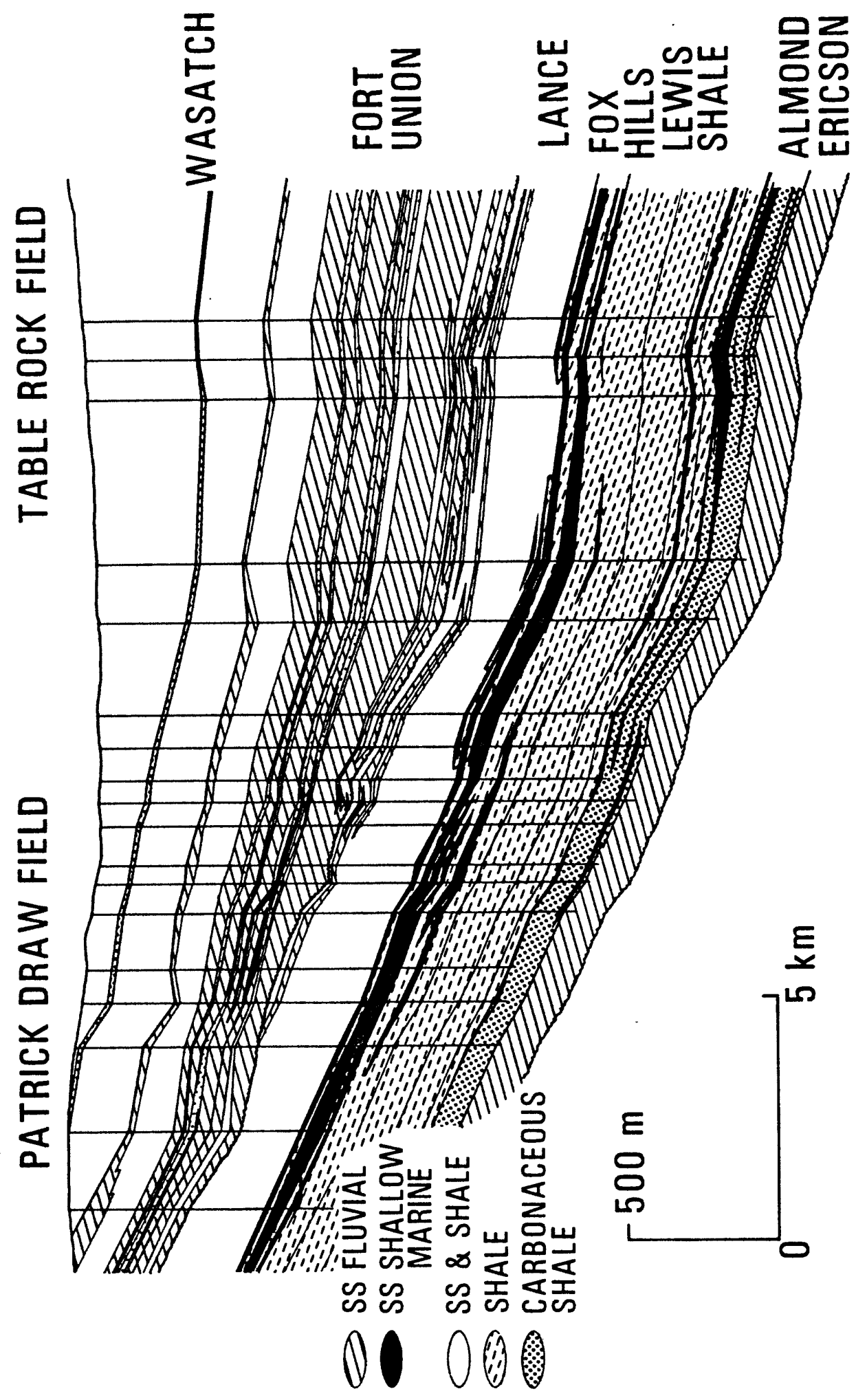

Figure 4 -- Stratigraphic cross section of Patrick Draw and Table Rock fields. Vertical lines show locations of wells that provided data used for control. Production is from the thin sandstone on top of the Almond Formation. 


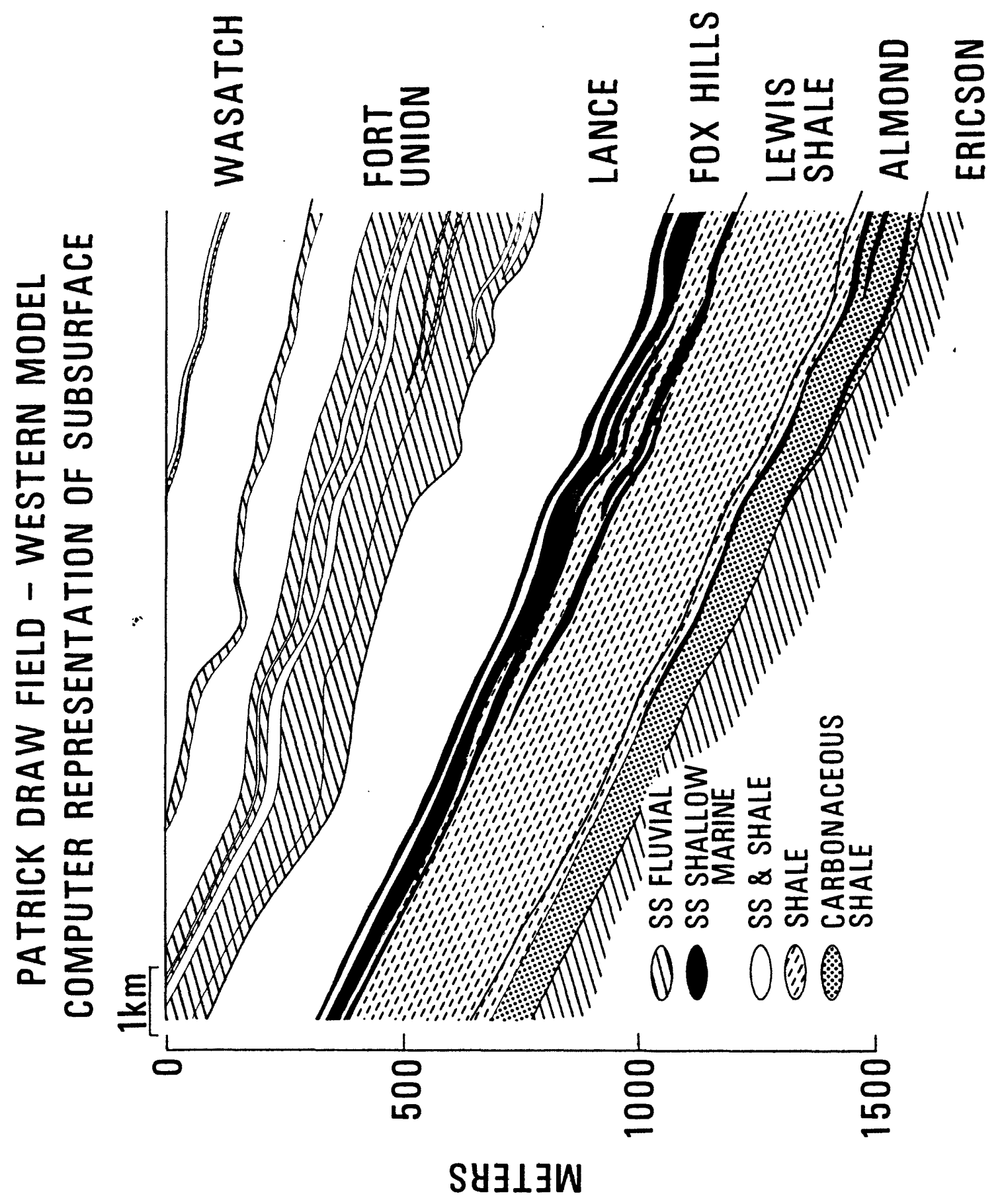

Figure 5 -- Computer-generated cross section of the western half of Patrick Draw field. 


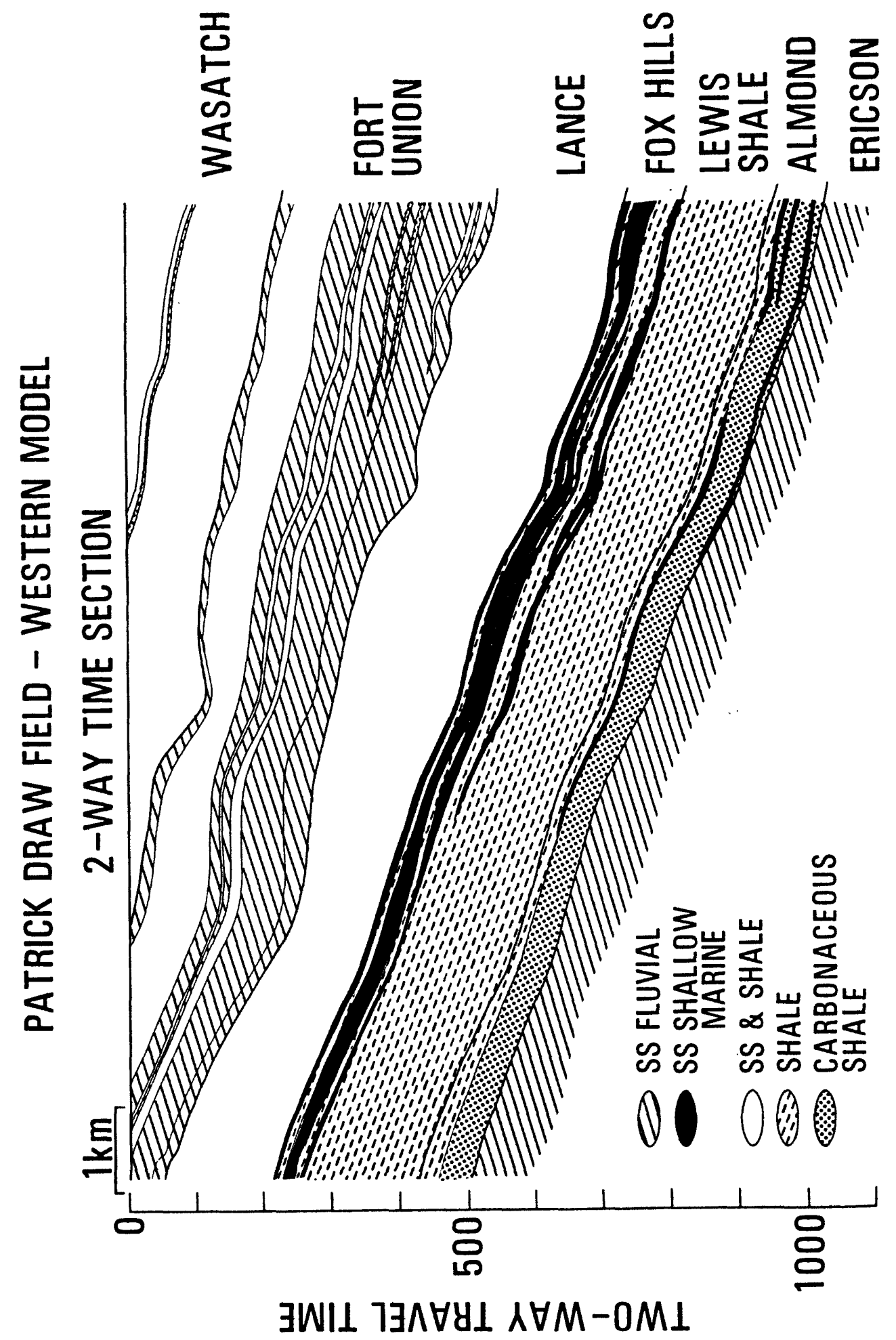

Figure 6 -- Computer-generated two-way time cross section of the western half of Patrick Draw field. This two-way time model was derived from the geologic model shown in figure 5. 







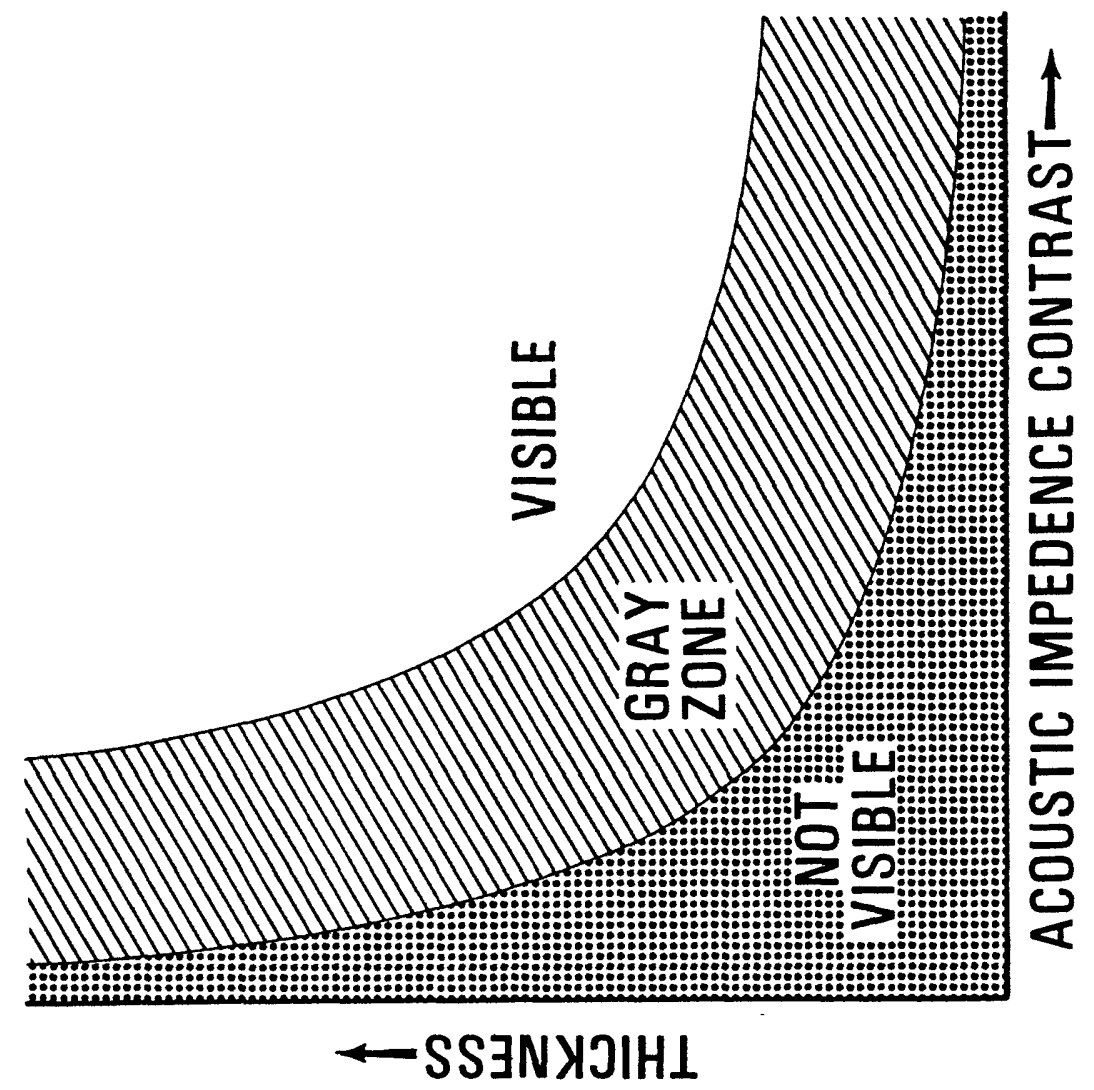

Figure 8 -- Diagrammatic plot showing the relationship between seismic acoustic impedance and bed thickness. Because of the combination of low acoustic impedance and bed thickness, the Patrick Draw field is either seismically "not visible" or in the "gray zone". 


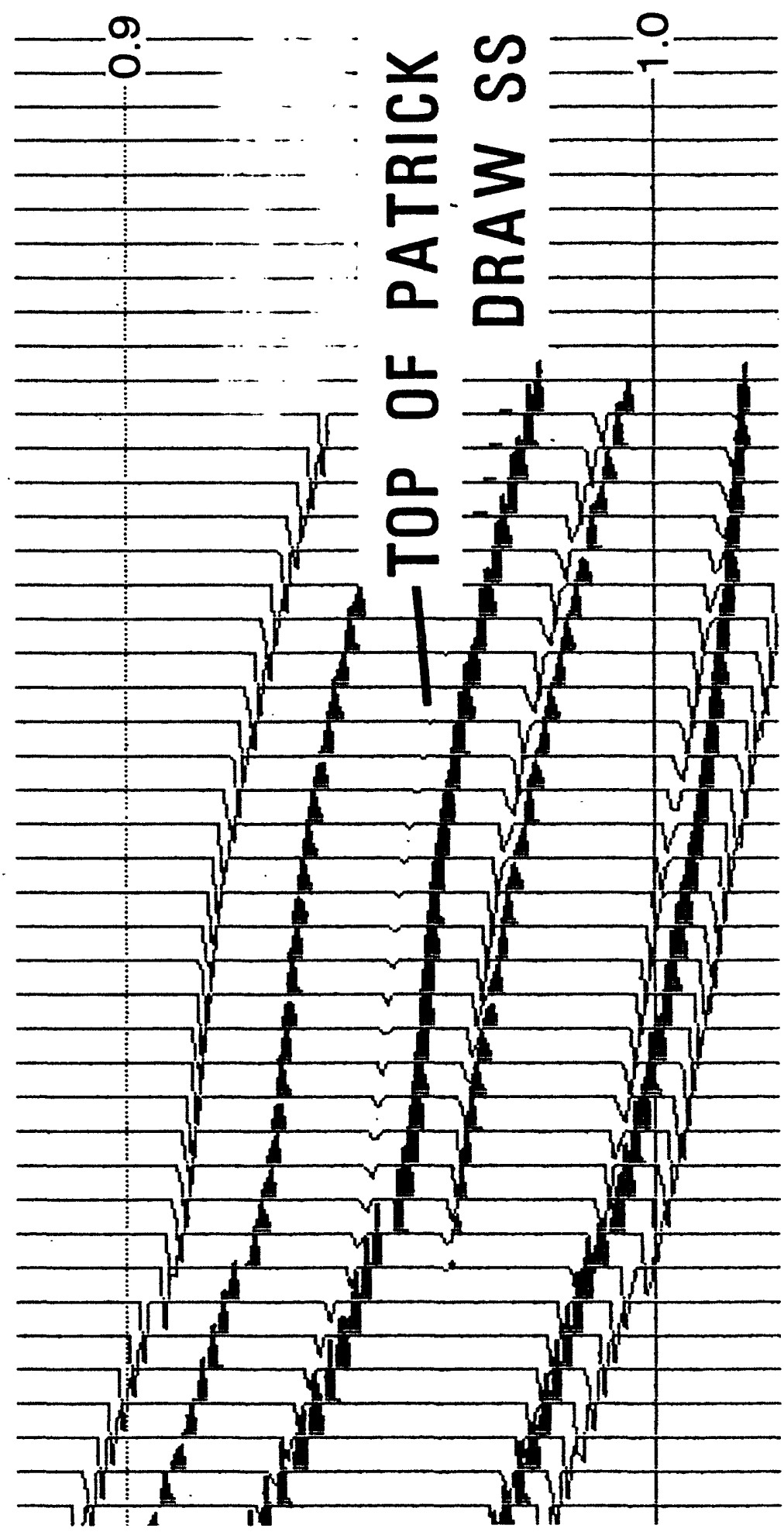

Figure 9 -- Close-up view of the lower righthand corner of the seismic model, figure 7 , showing the reflectivity spike series only. The top of the Patrick Draw reservoir sandstone is a very low amplitude spike with negative polarity. 




